\title{
The Impacts of Physical Exercise on Stress Coping and Well-Being in University Students in the Context of Leisure
}

\author{
Jong-Ho Kim*, Larry A. McKenzie \\ Department of Health Education and Recreation, Southern Illinois University, Carbondale, IL, USA \\ Email: ${ }^{*}$ taebie215@hanmail.net, mrbrink@siu.edu
}

Received 23 August 2014; revised 10 October 2014; accepted 26 October 2014

Copyright (C) 2014 by authors and Scientific Research Publishing Inc.

This work is licensed under the Creative Commons Attribution International License (CC BY).

http://creativecommons.org/licenses/by/4.0/

\section{(c) (i) Open Access}

\begin{abstract}
This study aims at investigating the in-depth information regarding impacts of physical exercise on psychological well-being in university students with an emphasis on coping with stress in the context of leisure. A qualitative research, based on interview to draw findings in an inductive way, was conducted. Nine university students $(N=9)$ in a large mid-west university took part in a faceto face, semi-structured interviews using ten open-ended questions with respect to benefits of leisure time physical exercise. The interview on the basis of phenomenological research examined what the participants experienced with leisure time physical exercise in conjunction with stress coping and mental health. Meaningful units of themes were induced with 24 initially drawn themes. These themes were reduced to 8 comprehensive constituent themes: self-efficacy, positive emotion, mind and body, health-behaviors, self-esteem, leisure, problem-focused coping, and positive expectancy. These reduced themes were finally boiled down to 6 integrated themes: positive emotion, unity of mind and body, heightened self-esteem, leisure, problem-focused coping, and self-regulation of health behavior. This research may shed a light in illuminating potential mechanism of how regular physical exercise is conducive to enhanced health behavior as well as effective stress coping in university students in the context of leisure. In particular, this research appears to be meaningful in suggesting that regular leisure-time physical exercise can lead to an effective problem-focused coping through elicitation of positive emotion.
\end{abstract}

\section{Keywords}

Physical Exercise, Leisure, Positive Emotion, Stress Coping, and Well-Being

${ }^{*}$ Corresponding author. 


\section{Introduction}

The mental health issue among university students has been growing public health implications with the high rates of depression, anxiety, and stress among university students. These mental health problems interfere with educational attainment, health development, social relationships, and quality of lives in the young adults [1]. Alcohol use disorder substantially increases among college students as compared to non-college aged youth counterparts [2]. Furthermore, suicide is the third leading cause of death among individuals aged 10 - 24 years old in the U.S. and the second commonest cause of death for young people between 15 - 34 years in Europe [3] [4]. In particular, university students are vulnerable to suffering from mental health problems due to their concerns regarding studies and their transition toward independence in emerging adulthood [5]-[7]. Nearly 60 percent of college students reported they had high levels of stress, anxiety, and depression [8] [9]. However, there has been a lack of stress coping skills among university students and many students tend to use ineffective stress coping methods [2] [10]-[12].

There has been numerous research studies conducted on benefits of exercise for mental health by supporting the theory that exercise is conducive to enhancing positive emotion such as vigor, pleasure, and energy as well as decreasing anxiety, tension, tiredness and anger [13] [14]. Also, a meta-analysis research finding corroborates that exercise contributes to enhancing mental health and buffering negative impact of stress [15]. People who engage in physical exercise are likely to have fewer stress symptoms and more psychological well-being than those who do not [16] [17].

Leisure, which is a broader context than physical exercise, is defined as an intrinsically motivating and selfendorsed activity in freer context in a person's life by pursuing enjoyment, self-expression, and meaningful engagement [18]. Active leisure is characterized by requiring some degree of physical exertion while passive leisure is associated with restful, recuperative, and quiet activity such as watching television, and listening to music. Social leisure which is neither active nor passive indicates leisure activity involving social interaction such as attending parties or clubs [19]. Leisure renders people an opportunity to experience flow which is referred to as a totally absorbed feeling, unaware of passage of time during engaging in leisure due to skill development, matching with challenge. Also, leisure contributes to building autonomy, social relationships, and optimism which enhance stress coping resources and personal well-being in the context of Self-Determination Theory in which intrinsic motivation leads to psychological well-being by enhancing competence, relatedness, and autonomy [18] [20] [21]. In addition, leisure eliciting positively-toned emotion contributes to not only breathers from stress but also involvement in pleasurable activity, which functions as an effective coping method in taxing situations. This positively-toned emotion, elicited from leisure, can restore hope or self-esteem, which buffer the deleterious impacts of stress [22]. Furthermore, Kieiber et al. [22] points out that positively-toned emotion leads to cognitive reappraisal in the face of stress.

Coping refers to a kind of behavioral or cognitive response or strategy to prevent or alleviate stress [23]. There are mainly two types of coping strategies: problem-focused coping and emotion-focused coping. Problemfocused coping refers to a way of coping through which people actively seek information or help to tackle a problem directly or diminish its impact, whereas emotion-focused coping refers to involvement in expressing emotion and altering expectation [23]. Problem-focused coping includes seeking counselors to get some advice to fix a problem, while emotion-focused coping includes blaming, venting, denying, avoiding, or just chatting with friends to express feelings. Emotion-focused coping, particularly characterized as avoidant types of coping, is highly associated with greater psychological dysfunction [24] [25]. However, effective emotion-focused coping can lead to better problem-focused coping through elicitation of positive emotion with a cleared and calm mindset [23]. This is consistent with the notion that positively-toned emotion by engaging in leisure contributes to cognitive reappraisal which helps to deal effectively with stress [22].

Although much research has demonstrated the effects of exercise on mental health, there has been a lack of research on impacts of physical activity on university students who may be vulnerable to mental health issues. Also, there has been a lack of research on physical exercise in the context of active leisure, which can be conducive to cognitive reappraisal. Furthermore, since much research has been conducted by using quantitative research in the area of exercise and mental health, there is a necessity to have in-depth information regarding how physical exercise contributes to effective stress coping in the context of leisure by conducting a qualitative research investigation. Also, this research aims to investigate how leisurely physical exercise is conducive to one's overall well-being. 


\section{Methods}

Phenomenological research was conducted by reflecting the benefits of physical exercise for one's well-being with an emphasis on stress coping and mental health in the context of leisure. This phenomenological research aims at drawing findings based on personal experiences of university students with regard to the impacts of regular leisure time physical exercise on their stress coping and well-being.

\subsection{Participants}

Semi-structured, face to face interviews were conducted with nine university students, consisting of seven males, and two females. The years in school of the participants were three juniors, three seniors, two master's students and one doctoral student. The representation of ethnicity is eight Caucasian and one African American. Levels of perceived stress of the participants fell into an average range $(M=13.78, S D=5.52)$ compared to the standard score in youths aged 18 - 29 [26]. The participants engaged in physical exercise approximately four times per week on average $(M=4.44, S D=2.03)$. The types of exercise they engaged in the most favorably were as follows: five participants replied aerobic exercise, which included jogging and fast walking by using treadmill, elliptical, exercise bike or outdoors; three participants replied anaerobic exercise which involved weight lifting; and one participant had been practicing yoga. Eight participants including one person, regulating outdoor jogging, have been using the recreation center on campus regularly to engage in physical exercise for their leisure. One participant had been engaging in yoga exercise in a yoga institute near the campus. All the participants had been engaging in physical exercise for a consistent period of time, ranging from three months to three and half years during their studies at the university.

\subsection{Sampling}

Research proposal was approved by the University’s Institutional Review Board (IRB) prior to start of the study. Flyers were posted at the recreation center and student center on the university campus to recruit participants for the study. Participants who were interested in taking part in an interview sent emails to the researcher. Also, the researcher was proactive to recruit subjects by randomly asking to interview students who were waiting for someone or taking a rest in the recreation center, student center or library. In addition, participants were randomly chosen based on the order in which the researcher encountered them in the recreation center. Participants who completed an interview along with a perceived stress scale, containing 10 short questions received $\$ 10$ compensation.

\subsection{Procedures}

Upon the completion of getting the consent form filled out as well as informing confidentiality, a semi-structured face to face interview started with a series of questions regarding background information relating to the duration of physical exercise, major, and year in school. Ten open-ended questions regarding participants' experience with leisure time physical exercise with an emphasis on stress coping were asked, and a few additional probing questions emerged during the interview to clarify insufficient or unclear responses. The interview questions were created by referring to previous research with respect to the ethnographic interview approach, benefits of exercise for mental health, and underlying concepts of leisure. The ethnographic interview approach in the context of friendly conversation was employed by using grand touring, descriptive, structural, and contrast questions [27]. The researcher who was trained for the qualitative research method conducted interviews at a café in the campus library and at the lobby at the student recreation center. The interviews were recorded using a tape recorder and lasted for approximately for 30 minutes for each participant. They were transcribed, and the replies (protocols) were analyzed after the researcher became familiar with them by reading the transcription carefully. The researcher analyzed the data using an existential phenomenological method [28]. Two researchers who are familiar with the phenomenological method independently analyzed the data and had a consensus on findings. The process used for the data analysis is as follow.

1. All the protocols were read repeatedly until making a sense of the whole main points

2. In each protocol, all sentences, phrases, or statement relevant to the experiences were drawn to form a list of meaningful units.

3. The meaningful units extracted from each protocol were categorized into their clusters, within each proto- 
col.

4. The clusters were merged into 24 overall constituent themes with psychologically coherent expressions.

5. The overall constituent themes were condensed down to 8 comprehensive constituent themes.

6. With the further integration, 6 final comprehensive constituent themes were drawn.

\section{Results}

The overall 24 constituent themes include self-confidence, leisure, problem-focused coping, enhanced focus, challenge, health behavior regulation, positive body image, stress reduction, healthier feelings, a sense of accomplishment, enhanced self-esteem, higher productivity, positive emotion, stronger body, energetic mind, positive expectancy, mind and body, flow, a sense of control, health prevention, active, taking time off, new insight, and release. These overall themes were reduced to 8 themes; self-efficacy, positive emotion, mind and body, health behavior regulation, self-esteem, leisure, problem-focused coping, and positive expectancy. These reduced themes were integrated into 6 final comprehensive themes; positive emotion, unity of mind and body, self-esteem, leisure, problem-focused coping, and health behavior regulation by selecting the higher order categories that seems to make sense based on previous research.

\section{1) Positive Emotion}

All of the participants responded that they experienced positive emotion elicited after engaging in physical exercise. The positive emotion seems to bring them a feeling of happiness and comfort about who they are more than before they engaged in physical exercise. People with high levels of stress before engaging in physical exercise seemed to alleviate perceived stress after finishing exercise due to positive emotion.

One participant who has been engaging in weight lifting and cardio exercise answered:

I think I am happier afterwards, more content with everything, I might be upset about something or maybe sad about something. Afterwards, after working out, I feel like that's all been lifted from me.

Also, the positive emotion elicited from engaging in physical exercise may enhance social relationships as a result. Another participant who has been engaging in a weight lifting replied:

I think most important thing for me is mood boost. You're always in a good mood, you're always active and energetic, mentally energetic too. I enjoy talking to people more stuff like that.

Positive emotion is conducive to building not only social relationships but also investing something new and engaging in a challenge. One participant who has been engaging in yoga replied:

I guess feeling of acceptance and also appreciation too. Wanting to see our challenges as challenges right?

Opportunities to figure something out and to learn whatever. It's emotionally positive.

The impact of regular physical exercise on positive emotion, leading to stress relief seems to be more salient among people with high levels of stress. One of the participants who engages in aerobic exercise replied:

When I did not regulate physical activity, just my overall mood was generally more pessimistic, I would get irritated a lot more easily when I wasn't exercising as often. It just helps me clear my mind so that I can focus on tasks at hand.

Overall, regardless of the participants' stress levels and types of exercise they engage in, positive emotion which elicits more focus, clarity in mind, and energetic mood after doing physical exercise seems to help people expand their social resources. In addition, positive emotion helps to deal with psychological distress more effectively.

\section{2) Unity of Mind and Body}

All participants mentioned that they have more improved well-being and life satisfaction from active leisure such as physical exercise than passive forms of leisure activity such as watching television or listening to music. One participant whose favorite physical activity is running replied:

Watching TV is good I mean I can only watch so much TV though but it doesn't relieve it may like sort of take my mind off of what I have to do little bit but it doesn't give me that relief of stress. Where at the gym, however, not only takes my mind off of the work but I'm also actually moving my body I'm doing something with my body that I think helps in reducing my amount of stress, and thus I feel better afterwards. But, watching a TV show is great 'cause I'm able to just sit on my couch and just watch but I'm still thinking about things that I have to do. Which does mean it doesn't really relieve stress.

Active leisure seems to be more effective to bring about mental health benefits through harmony between mind and body than other forms of leisure activities. One participant, who has been practicing yoga mentioned: 
At a certain level your life is physical. And I think what's nice about music is it encourages you to find harmony. And to listen to music also exposes you to different kinds of harmony especially if you're listening to actual music and not just crap on the radio. But I think exercise does something similar too. It encourages a certain felling of harmony but the difference is that some situations in life are physical. Like you have to hurry to get to the bus or you have to lift these groceries or you have to have a long day and doing physical activity enables you to even taking regular exercise enables you to find harmony even in those things. So I think it's similar to music but you know if you're really out of shape and you know you don't feel at home in your body then it's very easy to fall out of harmony. So I would say that you know listening to music and doing exercise right which are those are two most important things for early education for both Plato and Aristotle. Doing exercises and learning about music I think those things really do go together. When you're not comfortable in your body then it's easy to imagine your mind is something different from your body. And so you get issues of basically identity fracture basically wanting to be somewhere else. Wanting to live in a different world, in a different body, in a different reality and I think that in many ways that's the definition of bad mental health is wanting to be somewhere else and building an identity around being somewhere else.

People who are physically active may be more aware of their body conditions or health status due to the heightened sense of connection between mind and body. One participant who has been engaging in aerobic exercise replied:

Listening to music is very nice but I think still I would miss the physicality of working out of feeling connected and engaged to my body 'cause it's something we live in you know we have a consciousness, but it resides in our body and people I think don't often engage enough with their own bodies and you can become aware of it very much if you work out every day because you become familiar with how body feels in response to certain working outs. You know one day you say oh my arms is a little sore why is that? Or I feel more tired today, why is that? Or I have a cold I guess I'm feeling a little sick. I better not work out as hard. I think that people who are physically active regularly are more familiar with their own body and can sense when things are going wrong more easily.

\section{3) Heightened Self-Esteem}

A sense of accomplishment derived from engaging in physical exercise may bring a sense of self-esteem afterwards. One participant who has engaged in weight lifting mentioned:

I feel better I think after I engage in physical activity because it's just that sense of accomplishment that you did something you know? It gives you a good sense like you're not wasting your time you're actually getting out there and doing something that's good for you.

In addition, with regard to psychological and emotional benefits of doing physical exercise, another participant who has been engaging in running replied:

Just feeling better about myself really overall compared to not doing anything at all 'cause then I feel like I'm not doing anything. Like if I don't do physical activity I feel like I'm letting myself down I guess. But then when I am doing it I feel like I'm accomplishing something so I feel a lot better about myself that way.

Furthermore, when people reach a goal they set as they work out such as losing more weight or lifting heavier weight than before, they seem to have enhanced overall self-esteem through fostered self-confidence. One participant who has been engaging in weight lifting answered in response to psychological and emotional benefits of physical activity:

I think its self-confidence is a big part of it. You know, you're working towards a goal and everyday you get one step closer to reaching that goal you set for yourself. I mean I do these working outs every single day and my goal is to put on about two more pound of muscle and I'm working toward it slowly.

Taken together, regular physical exercise seems to be conducive to enhancing self-esteem in which people make progress toward reaching goals they set as well as achieving a sense of accomplishment after engaging in activities which challenge them.

\section{4) Leisure}

Leisure is defined as a freely chosen meaningful and enjoyable activity, outside of mandatory tasks [29]. Many participants seem to enjoy physical exercise as a leisure which is precious to invest free time for one's own health. This freely chosen activity may enhance stress coping due to a heightened sense of control over their spare time as well as health. One participant who has been engaging in aerobic exercise replied with regard to benefits of physical activity for mental health:

It's like one and a half to two hour break that I give myself everyday to just do something by myself and to not 
have to be responsible to anybody. Often time people have their cell phones with them all the time and I hate that because sometimes I don't want to talk to anybody. So when I work out usually if someone calls me I won't talk to them until after I'm done working out because that's my time and I think it's important for anybody to take back to own time for themselves because if you spend all the time doing work or always catering to the demand of everyone else you become very emotionally and mentally exhausted. So to have anytime for yourself is good.

Leisure also offers people an opportunity to be engrossed deeply in activity that they engage in due to the inherent nature of leisure, entailing self-determined and intrinsically motivated activity. One participant who has been practicing yoga replied:

Also, there's something about really being involved in some type of game or activity where you're just wholly invested. Your whole body is invested and paying attention to something and there are not many feelings like that. Or rather it's just a very special feeling to be totally caught up in something and to realize your body does things without you even realizing. So it's kind of a neat experience to see the way you can just be taken up in certain activities.

Leisure plays an important role in providing people with background in which they can take a rest when mentally distressed or exhausted in the face of stressors so that they can relax and get rejuvenated before solving their problems. One participant who has been practicing yoga answered:

You need to build up the context, and the external outside context to make the focused activity unique. So you can only do the focus when you have a background of other activity. So in a certain sense that regular exercise like the background, the comfortable background that enables you to focus on specific things. But if all you have is the specific thing, there's no background, there's nothing you can support on. Then of course you want to run away. In the same way for instance, if you have issues with parents often you don't know how to deal with those issues until you build up a life on your own away from your parents. My working acquaintance, you know my colleagues at work, my colleagues in school, keeping up regular relationships with family I don't have to be super in depth that's not the focus of my life but having a good relationship there is part of the healthy background. Eating well, taking care of brushing my teeth, just daily things that are basically capacity building or something. Or they encourage wanting to build habitual dimensions that I'm motivated in a certain sense and sometimes those become the focus of my activity very briefly but then the rest of the time they're part of the background.

In sum, leisure which is referred to as a freely chosen activity inherently derived from intrinsic motivation may provide a catalyst to be refreshed after respite, thus leading to problem-focused coping with a clearer mind, which is a healthy way of coping with stress.

\section{5) Problem-Focused Coping}

Positive emotion elicited from physical exercise may lead to better decision making with a clearer mind, thus fostering problem-focused coping such as seeking information to tackle problems rather than emotion-focused coping such as blaming, venting, denying, or avoiding [22] [30]. One participant who has been regularly running mentioned:

When I do exercise, it gives me time to think about it and really, you know, give me more time to judge what I should and should not do. So when I'm done I'm able to have a clear mind when it comes to deciding things as I was prior. I think about stuff when I run.

Tied back to the concept of leisure which involves taking a break from mandatory works or stressful situations, leisure may enhance refreshed feelings which may lead to better problem solving. The impact of this break may contribute to problem-focused coping. One participant who has been engaging in weight lifting replied:

When I go to the gym I kind of forget about everything and then going back to work you lose the stress but you can see exactly what you have to work on.

In addition, people who face difficulty or a stressful situation may be able to figure out the solution due to new insight after engaging in physical activity. One participant who has been engaging in aerobic exercise as well as weight lifting replied:

Sometimes I go to the gym it can allow me to sort of have a new insight, a new mindset so that afterwards I'm able to think through usually with new insights. So working out helps me to think through things... Things that were difficult for me to understand maybe become more clear after running and allowing my brain to process.

Overall, problem-focused coping can be elicited through heightened positive emotion, mental clarity, and focus which people may often experience after performing physical exercise.

6) Enhanced Health Behavior 
People who engage in physical exercise may be more likely to engage in other health behaviors such as healthy eating, avoidance of unhealthy food, and deep sleep. One participant who has been engaging in aerobic exercise replied:

I think it helps build the momentum if one can say oh like I mentioned I'm going to work out today so I need to eat a healthy breakfast, and then you get done working out and you think oh I was healthy so far I might as well keep eating healthy today. To build the momentum to think oh I worked out everyday, this week ya I might as well work out tomorrow too. Whereas one person says oh this morning I ate a terrible meal, I went out with my family we ate bacon and eggs and grilled potatoes I might as well just eat pizza for dinner 'cause today is a total loss. People build momentum either in a positive or negative direction and working out is part of a positive direction.

In addition, people seem to be more aware of health behavior after regular exercise. One participant who has been running replied:

I'm able to like I guess think about my everyday life in a different ways 'cause also at the gym I get to catch up on news I get to catch up on conversations with friends I get to I just get to really think about even when I'm eating whether or not I'm healthy or not.

Sense of control over time and health seems to be enhanced through regular physical exercise in the context of leisure. One participant who has been engaging in aerobic exercise replied:

College is kind of a hectic time in general. Stuff like my sleep schedule is just all over the place. So, exercise is one of the few things that I can regulate, I can regulate and have like complete control over. So overall it extremely increases my mood.

Overall, health behavior appears to be enhanced as a sense of control over health and time increases. This exercise behavior regulation seems to have a positive ripple effect on other aspects of health behavior including sleep, diet, and social relationship.

\section{Discussion}

The purpose of this research was to examine how physical exercise is conducive to reducing stress and enhancing overall well-being in university students. This research shows that leisure time physical exercise contributes to effective coping by enhancing better problem-focused coping derived from positive emotion. This is consistent with previous research which demonstrated effective emotion-focused coping, leading to better problemfocused coping with positively toned emotion elicited by engaging in leisure [22] [23]. It is noteworthy that most of the participants replied that they have experienced a clear mind and focus, derived from positively toned emotion after engaging in leisurely physical exercise, which helps them to capitalize on effective problem focused coping, as well as problem solving efficacy. Also, two of the participants directly mentioned that they take a more proactive approach to problem solving in the face of stress rather than avoiding the situation or blaming others. This approach type of coping as opposed to an avoidance type of coping may play an important role in coping with stress effectively. Planned breather leisure coping style is positively associated with masteryoriented goals, effective time management and negatively associated with procrastination. On the contrary, avoidant type of coping style is negatively correlated with mastery-oriented goals and effective time management and positively associated with procrastination [31]. The approach type of coping appears to be derived from eliciting positive emotion, leading to cognitive reappraisal in the face of stress [22] [32].

Also, all participants mentioned that physical exercise seems to be more effective in reducing stress than passive forms of leisure such as watching TV or even social leisure, such as meeting with friends. This also warrants further studying in terms of active leisure in comparison with passive leisure. The current study seems to have brought up an important message in this respect. First, many leisure activities are characterized with using physicality as life does, contributing to one's well-being through enhancing a mind and body connection in a holistic way. Many people seem to have clear and immediate benefits by inducing balance and harmony between mind and body by engaging in leisure time physical activity, which contributes to mental health as well as physical health. Physical imbalance, such as excessive consumption of a high fat in diet or overeating without burning calories through physical activity, can elevate risks of chronic diseases, associated with obesity, such as diabetes, high blood pressure, and high cholesterol levels, which in turn, have negative impacts on psychological well-being [33]. It is well-documented that obesity increases the risk of mental health disorders through poorer perceived health, low self-esteem, body image concerns, weight-related stigma and bias, increased rate of chro- 
nic disease, or dieting and binge eating [34] [35]. In addition, patients with chronic conditions, such as diabetes, congestive heart failure, and arthritis, elevate the risk of deteriorating well-being and psychosocial functioning [36] [37]. Conversely, mental illnesses can trigger physical illnesses as well as obesity by altering hormonal balances and sleep cycles, impairing social and cognitive functions, and decreasing energy levels, which can negatively impact the adoptions of health behaviors [38]. Therefore, mind and body interacts reciprocally and synergistically as a unity in this respect and leisure time physical activity may play a crucial role in enhancing the well-balanced health through an elicitation of positive emotion coupled with physical movement/fitness. Previous research substantiates the notion that improved physical health conditions through physical activity combined with a stress management program was effective in enhancing psychological well-being as well as improving physiological health indicators such as cholesterol and blood sugar [39].

Also, health behavior regulation enhanced by engaging in physical exercise is consistent with previous research that health promoting behaviors have ripple effects on other health behaviors. Physical activity is positively associated with healthy diet and negatively associated with smoking [40]. In particular, in the context of leisure, physical exercise may lead to health promoting behaviors due to the fact that people have enhanced sense of control over their time and health status. This may be the reason that people are more motivated to engage in physical exercise for a long time through enhanced sense of control, which in turn, lead to psychological and physical well-being in the light of leisure [18] [19] [41] [42]. Since leisure pertain to the notion in which people engage in a freely chosen activity outside of obligatory works, leisure activity can lend itself a sense of freedom and autonomy which contribute to enhancing sense of control [22] [28] [43]. In a similar vein, the selfdetermination disposition in leisure contributes to enhanced sense of control and intrinsic motivation which function as a stress coping resource [41] [44]. Previous research corroborate that a sense of control is conducive to enhancing health promoting behaviors by fostering motivational forces, affecting health behaviors or conferring a resource, positively impacting the way people react to stressors [45]-[47].

In addition, positive emotion elicited through active leisure, which can contribute to health behavior is a compelling finding inductively drawn from the interview, which deserves a further research attention in this area. The link between positive emotion and health is aligned with previous research demonstrating positive emotion can lead to health outcomes through strengthened immune and cardiovascular systems, induced by enhancing social ties and health practices including regular physical exercise, optimal quality and quantity of sleep, and healthy diet [48] [49]. Also, participations in restorative activities such as sleep, exercise, relaxation, vocation, interacting with social ties, and spending time in natural environment are conducive to reducing stress appraisal and negative affective response to stress [50]. Also, Smith and Baum point out that positive emotion plays a crucial role in protecting individuals from negative response to stress through release of endogenous opioids. The findings in the qualitative research appear to further illuminate the pathways of how leisure time physical exercise contributes to well-being. Further research with longitudinal and experimental designs need to replicate whether or not positive emotion elicited from various types of leisure contributes to physical health as well as mental health by generating effective stress coping strategies.

There are some limitations in the research. Since it was conducted by using university students on a single campus, the findings may be difficult to be generalized for an entire population. Also, participants in this study were already motivated to engage in physical exercise before participating in the study. This may be a threat to selection bias which may trigger a transferability issue when it is applied to other settings where participants are not sufficiently motivated to engage in physical exercise in their free time. Further research need to be conducted by including a variety of populations with multiple study designs including an experimental research or a longitudinal research in order to increase the transferability of the study.

In addition, the participants in the study are dominantly Caucasian males. The proportion of male participants is seven out of nine and the ethnicity of the participants consists of eight Caucasian and one African American. However, previous research show that perceived stress is relatively higher among female college students as well as minority college students, [1] [10] [12] [51]. Thus, recruiting more females for a proportionately balanced sample with males might have contributed to better understanding for underlying reasons of engaging in physical exercise for stress management and psychological well-being. Nevertheless, given the findings from the previous research regarding the susceptibility to stress across gender and ethnicity, it can be a promising result in that white male oriented sample in the study has drawn the finding showing the positive impacts of leisure time physical activity on stress coping and well-being. This is due to the fact that people with higher stress levels indicates more room to improve through leisure benefits as compared to those with lower levels of stress at 
baseline [41]. Although the average participants' stress levels based on the measure on Perceived Stress Scale as well as overrepresentation of white male in the study could have contributed to presumably lower improvements in stress as compared to a proportionally representative sample, the substantial effects of leisure time physical activity on alleviating stress drawn from all the participants are noteworthy.

Also, there is a variety of physical exercises, for instance, aerobic exercise, anaerobic exercise or mind-body exercise, which may have varying degree of influences on mental health and stress coping. Nevertheless, these findings of the positive impacts of physical exercise on effective stress coping and health through elicitation of positive emotion, unequivocally drawn from all the participants who engage in different types of leisure time physical exercise, would shed light on further research on the benefits of active leisure for one's psychological well-being with an emphasis on positive emotion, derived from physical activity. In addition, this finding also can contribute to yielding an implication that any types of physical activity performed in the context of leisure in which participants engage in freely chosen activities would be conducive to enhancing positive emotion, buffering against stress effectively. This is consistent with the previous research demonstrating the benefits of physical exercise for mental health is significantly pronounced in the context of leisure involving participants' personal choice and purely recreational pursuits regardless of types of exercises requiring different levels of energy expenditures [52].

\section{Conclusion}

This research, which explores the in-depth information regarding the potential mechanisms between physical exercise and well-being in the context of leisure, appears to be meaningful in suggesting a hint that leisure-time physical exercise contributes to effective problem-focused coping through elicitation of positive emotion. The enhanced coping with stress, in turn, can influence the regulation of health behaviors, thus leading to overall well-being.

\section{Acknowledgements}

The authors appreciate Dr. Stephen L. Brown who gave constructive feedback in conducting the research and also thank the participants who took part in the interview for the study.

\section{References}

[1] Bayram, N. and Bilgel, N. (2008) The Prevalence and Socio-Demographic Correlations of Depression, Anxiety and Stress among a Group of University Students. Social Psychiatry Psychiatric Epidemiology, 43, 667-672. http://dx.doi.org/10.1007/s00127-008-0345-X

[2] Blanco, C., Okuda, M., Wright, C., Hasin, D.S., Grant, B.F., Liu, S.-M. and Olfson, M. (2008) Mental Health of College Students and Their Non-College Attending Peers: Results from the National Epidemiologic Study on Alcohol and Related Conditions. Archives of General Psychiatry, 65, 1429-1437. http://dx.doi.org/10.1001/archpsyc.65.12.1429

[3] Centers for Disease Control (2007) Suicide Trends among Youths and Young Adults Aged 10-24 Years United States, 1990-2004. Morbidity and Mortality Weekly Report, 56, 905-908.

[4] World Health Organization (2014) Suicide Prevention (SUPRE). http://www.who.int/mental_health/prevention/suicide/suicideprevent/en/

[5] Arnett, J.J. (2000) Emerging Adulthood: A Theory of Development from the Late Teen through Twenties. American Psychologist, 55, 469-480. http://dx.doi.org/10.1037/0003-066X.55.5.469

[6] Bewick, B., Koutsopoulou, G., Miles, J., Slaa, E. and Barkham, M. (2010) Changes in Undergraduate Students’ Psychological Well-Being as They Progress through University. Studies in Higher Education, 35, 633-645. http://dx.doi.org/10.1080/03075070903216643

[7] Wardle, J., Steptoe, A., Grulis, G., Sek, H., Todorova, I., Vogele, C. and Ziarko, M. (2004) Depression, Perceived Control, and Life Satisfaction in University Students from Central-Eastern and Western Europe. International Journal of Behavioral Medicine, 11, 27-36. http://dx.doi.org/10.1207/s15327558ijbm1101_4

[8] Inam, S.N., Saqib, A. and Alam, E. (2003). Prevalence if Anxiety and Depression among Medical Students of a Private University. Journal of the Pakistani Medical Association, 53, 44-47.

[9] Makrides, L., Veinot, P., Richard, J., McKee, E. and Gallivan, T. (1998) A Cardiovascular Health Needs Assessment of University Students Living in Residence. Canadian Journal of Public Health, 89, 171-175.

[10] Brougham, R.R., Zail, C.M., Mendoza, C.M. and Miller, J.R. (2009) Stress, Sex Differences, and Coping Strategies 
among College Students. Current Psychology, 28, 85-97. http://dx.doi.org/10.1007/s12144-009-9047-0

[11] Campbell, R.L., Svenson, L.W. and Jarvis, G.K. (1992) Perceived Level of Stress among University Undergraduate Students in Edmonton, Canada. Perceptual and Motor Skills, 75, 552-554. http://dx.doi.org/10.2466/pms.1992.75.2.552

[12] Nguyen-Michel, S.T., Unger, J.B. and Spruijt-Metz, D. (2006) Associations between Physical Activity and Perceived Stress/Hassles in College Students. Stress and Health, 22, 179-188. http://dx.doi.org/10.1002/smi.1094

[13] Thaylor, S.E. (1987) Energy, Tiredness, and Effects of Sugar Snack versus Moderate Exercise. Journal of Personality and Social Psychology, 52, 119-125. http://dx.doi.org/10.1037/0022-3514.52.1.119

[14] Woo, M., Kim, S., Kim, J., Petruzzello, S.J. and Hatfield, B.D. (2009) Examining the Exercise-Effect Dose-Response Relationship: Does Duration Influence Frontal EEG Asymmetry? International Journal of Psychophysiology, 72, 166172. http://dx.doi.org/10.1016/j.ijpsycho.2008.12.003

[15] Salmon, P. (2001) Effects of Physical Exercise on Anxiety, Depression, and Sensitivity to Stress: A Unifying Theory. Clinical Psychology Review, 21, 33-61. http://dx.doi.org/10.1016/S0272-7358(99)00032-X

[16] Edward, S. (2006) Physical Exercise and Psychological Well-Being. South African Journal of Psychology, 36, 357-373. http://dx.doi.org/10.1177/008124630603600209

[17] Norris, R., Carroll, D. and Cochrane, R. (1992) The Effect of Physical Activity and Exercise Training on Psychological Stress and Well-Being in an Adolescent Population. Journal of Psychosomatic Research, 36, 55-65. http://dx.doi.org/10.1016/0022-3999(92)90114-H

[18] Caldwell, L.L. (2005) Leisure and Health: Why Is Leisure Therapeutic? British Journal of Guidance and Counselling, 33, 7-26. http://dx.doi.org/10.1080/03069880412331335939

[19] Joudrey, A.D. and Wallace, J.E. (2009) Leisure as a Coping Resource: A Test of the Job Demand-Control-Support Model. Human Relations, 62, 195-217. http://dx.doi.org/10.1177/0018726708100357

[20] Deci, E.L. and Ryan, R.M. (1985) Intrinsic Motivation and Self-Determination in Human Behavior. Plenum, New York. http://dx.doi.org/10.1007/978-1-4899-2271-7

[21] Ryan, R. and Deci, E.L. (2000) Self-Determinism Theory and the Facilitation of Intrinsic Motivation, Social Development, and Well-Being. American Psychology, 55, 68-78. http://dx.doi.org/10.1037/0003-066X.55.1.68

[22] Kleiber, D.A., Hutchinson, S.L. and Williams, R. (2002) Leisure as a Resource in Transcending Negative Life Events: Self-Protection, Self-Restoration, and Personal Transformation. Leisure Sciences, 24, 219-235. http://dx.doi.org/10.1080/01490400252900167

[23] Carver, C.S. and Connor-Smith, J. (2010) Personality and Coping. Annual Review of Psychology, 61, 679-704. http://dx.doi.org/10.1146/annurev.psych.093008.100352

[24] Beasley, M., Thompson, T. and Davidson, J. (2003) Resilience in Response to Life Stress: the Effects of Coping Style and Cognitive Hardness. Personality and Individual Differences, 34, 77-95. http://dx.doi.org/10.1016/S0191-8869(02)00027-2

[25] Higgins, J.E. and Endler, N.S. (1995) Coping, Life Stress, and Psychological and Somatic Distress. European Journal of Personality, 9, 253-270. http://dx.doi.org/10.1002/per.2410090403

[26] Cohen, S. and Williamson, G.M. (1988) Perceived Stress in a Probability Sample of the United States. In: Spacapan, S. and Oskamp, S., Eds., The Social Psychology of Health, Newbury Park, CA, Sage, 31-67.

[27] Spradley, J.P. (1979) The Ethnographic Interview. Holt, Rinehart and Winston, New York.

[28] Giorgi, A. (1975) An Application of Phenomenological Method in Psychology. In: Giorgi, A., Fischer, C. and Murray, E., Eds., Duquesne Studies in Phenomenological Psychology, Duquesne University Press, Pittsburg, 82-103.

[29] Godbey, G. (1994) Leisure in Your Life: An Exploration. Venture Publishing, State College.

[30] Wenzel, L., Glanz, K. and Lerman, C. (2002) Stress, Coping, and Health Behavior. In: Glanz, K., Rimer, B.K. and Lewis, F.M., Eds., Health Behavior and Health Education: Theory, Research, and Practice, Jossey-Bass, San Francisco, 210-239.

[31] Patry, D.A., Blanchard, C.M. and Mask, L. (2007) Measuring University Students’ Regulatory Leisure Coping Styles: Planned Breathers or Avoidance? Leisure Sciences, 29, 247-265. http://dx.doi.org/10.1080/01490400701257963

[32] Iwasaki, Y., Mactavish, J. and Mackey, K. (2005) Building on the Strengths and Resilience: Leisure as a Stress Survival Strategy. British Journal of Guidance and Counseling, 33, 81-100. http://dx.doi.org/10.1080/03069880412331335894

[33] Sacco, W.P., Wells, K.J., Friedman, A., Matthew, R., Perez, S. and Vaughan, C.A. (2007) Adherence, Body Mass Index, and Depression in Adults with Type 2 Diabetes: the Mediational Role of Diabetes Symptoms and Self-Efficacy. Health Psychology, 26, 693-700. http://dx.doi.org/10.1037/0278-6133.26.6.693 
[34] Doll, H.A., Petersen, S.E. and Stewart-Brown, S.L. (2000) Obesity and Physical and Emotional Well-Being: Associations between Body Mass Index, Chronic Illness, and Physical and Mental Components of the SF-36 Questionnaire. Obesity Research, 8, 160-170. http://dx.doi.org/10.1038/oby.2000.17

[35] Gatineau, M. and Dent, M. (2011) Obesity and Mental Health. National Obesity Observatory, Oxford.

[36] Cadman, D., Boyle, M., Szatmari, P. and Offord, D.R. (1987) Chronic Illness, Disability, and Mental and Social WellBeing: Findings of the Ontario Child Health Study. Pediatrics, 79, 805-813.

[37] Stewart, A.L., Greenfield, S., Hays, R., Wells, K., Rogers, W.H., Berry, S.D., McGlynn, E.A. and Ware, J.E. (1989) Functional Status and Well-Being of Patients with Chronic Conditions: Results from the Medical Outcomes Study. The Journal of the American Medical Association, 262, 907-913. http://dx.doi.org/10.1001/jama.1989.03430070055030

[38] Canadian Mental Health Association, Ontario (2008) The Relationship between Mental Health, Mental Illness and Chronic Physical Conditions. 1-9. http://ontario.cmha.ca/public_policy/the-relationship-between-mental-health-mental-illness-and-chronic-physical-condi $\underline{\text { tions/ }}$

[39] Berger, R., Gidron, Y., Harman-Boehm, I., Dekel, G., Shwartzman, P. and Sarid, O. (2007) An Integrative CognitiveBehavioral Approach for the Treatment for Type 2 Diabetes Miletus: A Pilot Study. The Endocrinologist, 17, 122-126. http://dx.doi.org/10.1097/01.ten.0000261461.61325.90

[40] Lippke, S., Nigg, C. and Maddock, J. (2012) Health-Promoting and Health-Risk Behaviors: Theory-Driven Analyses of Multiple Health Behavior Change in Three International Samples. International Journal of Behavioral Medicine, 19, 1-13. http://dx.doi.org/10.1007/s12529-010-9135-4

[41] Coleman, D. and Iso-Ahola, S.E. (1993) Leisure and Health: The Role of Social Support and Self-Determination. Journal of Leisure Research, 25, 111-128.

[42] Iso-Ahola, S.E. (2013) Exercise: Why It Is a Challenge for Both the Nonconscious and Conscious Mind. Review of General Psychology, 17, 93-110. http://dx.doi.org/10.1037/a0030657

[43] Kelly, J.R. (1996) Leisure. Allyn \& Bacon, Needham Height.

[44] Iwasaki, Y. and Mannell, R.C. (2000) Hierarchical Dimensions of Leisure Stress Coping. Leisure Sciences, 22, 163181. http://dx.doi.org/10.1080/01490409950121843

[45] DeVellis, B.M. and DeVellis, R.F. (2001) Self-Efficacy and Health. In: Baum, A.T., Revenson, A.T. and Singer, J.E., Eds., Handbook of Health Psychology, Erlbaum, Mahwah, 235-247.

[46] Skaff, M.M. (2007) Sense of Control and Health. In: Aldwin, C.M., Park, C.L. and Spiro III, A., Eds., Handbook of Health Psychology and Aging, Guilford Press, New York, 186-209.

[47] Pearlin, L.I., Lieberman, M.A., Menaghan, E.G. and Mullan, J.T. (1981) The Stress Process. Journal of Health and Social Behavior, 22, 337-356. http://dx.doi.org/10.2307/2136676

[48] Pressman, S.D. and Cohen, S. (2005) Does Positive Affect Influence Health? Psychological Bulletin, 131, $925-971$. http://dx.doi.org/10.1037/0033-2909.131.6.925

[49] Tugade, M.M., Fredrickson, B.L. and Barrett, L.F. (2004) Psychological Resilience and Positive Emotional Granularity: Examining the Benefits of Positive Emotions on Coping and Health. Journal of Personality, 72, 1161-1190. http://dx.doi.org/10.1111/j.1467-6494.2004.00294.x

[50] Smith, A.W. and Baum, A. (2003) The Influence of Psychological Factors on Restorative Function in Health and Illness. In: Suls, J. and Wallston, K.A., Eds., Social Psychological Foundations of Health and Illness, Blackwell Publishing, Malden, 431-457. http://dx.doi.org/10.1002/9780470753552.ch16

[51] Rosenthal, B.S. and Schreiner, A.C. (2000) Prevalence of Psychological Symptoms among Undergraduate Students in an Ethnically Diverse Urban Public College. Journal of American College Health, 49, 12-18. http://dx.doi.org/10.1080/07448480009596277

[52] Stephens, T. (1988) Physical Activity and Mental Health in the United States and Canada: Evidence from Four Population Surveys. Preventive Medicine, 17, 35-47. http://dx.doi.org/10.1016/0091-7435(88)90070-9 
Scientific Research Publishing (SCIRP) is one of the largest Open Access journal publishers. It is currently publishing more than 200 open access, online, peer-reviewed journals covering a wide range of academic disciplines. SCIRP serves the worldwide academic communities and contributes to the progress and application of science with its publication.

Other selected journals from SCIRP are listed as below. Submit your manuscript to us via either submit@scirp.org or Online Submission Portal.
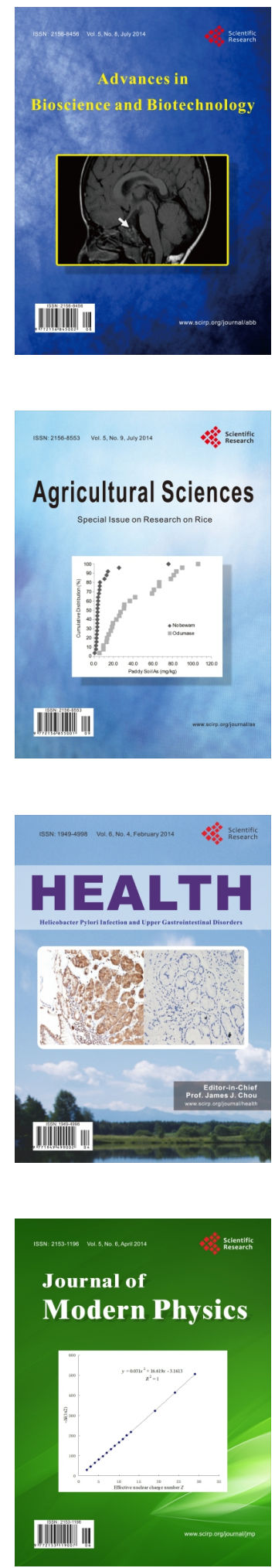
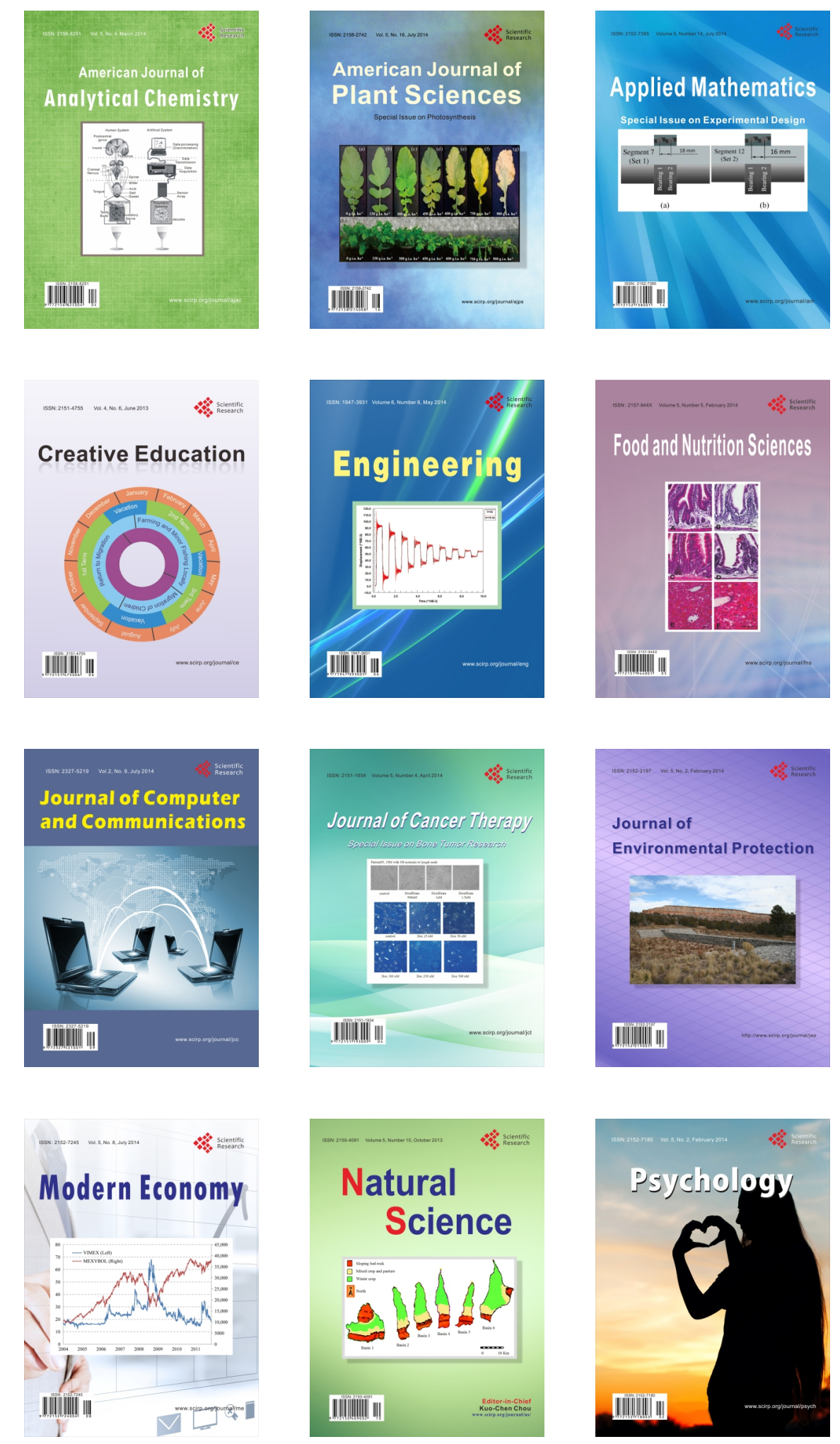